OPEN ACCESS

Edited by:

Mithila Jugulam,

Kansas State University, United States

Reviewed by:

Simerjeet Kaur,

Punjab Agricultural University, India

Maor Matzrafi,

Volcani Center, Israel

${ }^{*}$ Correspondence:

Franck E. Dayan

franck.dayan@colostate.edu

Specialty section

This article was submitted to

Weed Management,

a section of the journal

Frontiers in Agronomy

Received: 23 October 2021 Accepted: 29 November 2021

Published: 11 January 2022

Citation:

Bough RA, Gaines TA and Dayan FE

(2022) Low Temperature Delays Metabolism of Quizalofop in Resistant Winter Wheat and Three Annual Grass Weed Species.

Front. Agron. 3:800731 doi: 10.3389/fagro.2021.800731

\section{Low Temperature Delays Metabolism of Quizalofop in Resistant Winter Wheat and Three Annual Grass Weed Species}

\author{
Raven A. Bough, Todd A. Gaines and Franck E. Dayan* \\ Department of Agricultural Biology, Colorado State University, Fort Collins, CO, United States
}

Quizalofop-resistant wheat is the core component of the recently commercialized CoAXium ${ }^{\text {TM }}$ Wheat Production System. As with other herbicides, quizalofop provides better weed control at early growth stages and under optimum temperature. However, in regions with winter wheat production, quizalofop application may be affected by unpredictable, rapid temperature decreases. Temperature shifts can cause crop injury or impact weed control efficacy. In the following study, we examine the effect of reduced temperature on quizalofop content and metabolism in CoAXium ${ }^{\mathrm{TM}}$ winter wheat and three winter weed species: downy brome (Bromus tectorum L.), feral rye (Secale cereale L.), and jointed goatgrass (Aegilops cylindrica Host). Temperature conditions include either 19 or $4.5^{\circ} \mathrm{C}$ daytime temperatures with tissue sampling over 5 timepoints (1-16 or 18 days after treatment, DAT). Analysis features liquid chromatography coupled to tandem mass spectrometry detection of the active form of quizalofop, quizalofop acid. Quizalofop content trends reveal delayed metabolism under cooler conditions for wheat and weeds. Quizalofop content peaks within 1-2 DAT in the warmer temperatures for all species and decreases thereafter. In contrast, content peaks between 8 and 9 DAT at cooler temperatures except for downy brome. Minimal decreases in content over time generally follow cooler temperature peaks. Further, the absence of differences in maximum quizalofop content in all species suggests absorption and/or de-esterification of quizalofop proherbicide to the active form is not reduced at cooler temperatures. Final dry shoot tissue biomass does not necessarily correspond to differences in metabolism, as biomass of wheat treated with a field rate of quizalofop does not differ between temperatures. Weeds were treated with sublethal doses of quizalofop in order to monitor herbicide metabolism without causing plant death. Under this condition, weed biomass only differs for jointed goatgrass, which has a greater biomass in the cooler temperature.

Keywords: herbicide metabolism, CoAXium wheat production system, Aggressor herbicide, herbicide absorption, herbicide selectivity, feral rye, jointed goatgrass, downy brome 


\section{INTRODUCTION}

The CoAXium ${ }^{\mathrm{TM}}$ Wheat Production System centers on wheat with the AXigen ${ }^{\mathrm{TM}}$ trait for quizalofop resistance (Bough et al., 2021). The $\operatorname{AXigen}^{\mathrm{TM}}$ trait is an alanine to valine mutation at position 2004 of wheat acetyl-CoA carboxylase (ACCase) (Ostlie et al., 2015) causing an enzyme conformational change that imparts resistance to quizalofop acid (QZA) (Bough and Dayan, 2021). The original QZA-resistant winter wheat mutant accessions were discovered at Colorado State University. Homozygous resistance mutations in two of three wheat sub-genomes were introgressed into a susceptible elite genetic background. High-performing progeny were selected and released as initial CoAXium ${ }^{\mathrm{TM}}$ varieties in partnership with the Colorado Wheat Research Foundation, LLC. The system provides effective post-emergence control of annual weedy grasses in winter wheat where control options are limited, and it is paired with a stewardship program to mitigate development of herbicide-resistant weeds.

The CoAXium ${ }^{\mathrm{TM}}$ Wheat Production System consists of a customized proherbicide quizalofop-p ethyl (QPE) formulation under the tradename Aggressor ${ }^{\mathrm{TM}}$. The proherbicide passively penetrates cuticle tissue and is subsequently bioactivated to the active QZA form by carboxyesterases in wheat and other grass species (Haslam et al., 2001; Cummins and Edwards, 2004).

Although QPE application is more desirable at early growth stages in winter wheat (i.e., 4th leaf stage) to provide maximal weed control, environmental conditions may rapidly change from ideal to sub-optimal after treatment. Spring herbicide applications in High Plains winter wheat production are particularly risky due to unpredicted weather shifts that can cause sudden temperature plunges, as decreased temperatures proceeding herbicide application may result in unintended crop injury. For example, cooler temperatures causes crop injury after the application of 2,4-D alone or in combination with dichlorprop, as well as a mixture of dicamba, MCPA, and mecoprop in a Canadian winter wheat study (Robinson et al., 2015).

Plants acclimated to cold may tolerate herbicides despite reduced temperatures, as is the case with rice (Oryza sativa L.) and bispyribac (Martini et al., 2021). Conversely, reduced temperatures generally suppress plant growth and slow metabolism, especially in plants that have been dehardened, or lost acclimation to cool temperatures as is the case for most plants in spring. One reason for this is that most enzymes have an optimal temperature range and deviations from the optimal range cause decreased enzyme activity. Optimal enzyme temperature ranges are typically above freezing. Further, herbicide absorption, translocation, accumulation, metabolism, and sequestration may be impeded at low temperatures (Kudsk and Kristensen, 1992; Ghanizadeh and Harrington, 2017), which may explain crop injury due to otherwise safe herbicides.

In some cases, herbicide efficacy depends on temperature, where either low or high temperatures can negatively affect efficacy through alterations in herbicide movement or metabolism. Effects of temperature on herbicide efficacy may be species dependent, as demonstrated by a study where increasing the air temperature from 18 to $30^{\circ} \mathrm{C}$ reduces fluazifop efficacy on green foxtail [Setaria viridis (L.) P. Beauv.] at low herbicide rates but does not affect Japanese millet (Echinochloa frumentaceae Link) control (Smeda and Putnam, 1990). A different study of 2,4-D and glyphosate herbicide efficacy on common (Ambrosia artemisiifolia L.) and giant ragweed (A. trifida L.) reveals improved efficacy at higher temperatures $\left(29^{\circ} \mathrm{C}\right.$ daytime $/ 17^{\circ} \mathrm{C}$ night vs. $20^{\circ} \mathrm{C} / 11^{\circ} \mathrm{C}$ ) due to increased absorption and translocation, irrespective of biotype susceptibility or resistance (Ganie et al., 2017). Optimal temperatures for enzyme activity associated with herbicide metabolism varies, where optimal temperatures typically enhance herbicide detoxification in weeds. Pyrithiobac suppresses growth of Palmer amaranth (Amaranthus palmeri S. Wats.) most at a moderate temperature $\left(27^{\circ} \mathrm{C}\right)$ compared to low $\left(18^{\circ} \mathrm{C}\right)$ or high $\left(40^{\circ} \mathrm{C}\right)$ temperatures (Mahan et al., 2004). The researchers propose that moderate, suboptimal temperatures reduce the activity of enzymes involved in metabolism at the moderate temperature, but that low or high temperature conditions enhance activity and therefore result in decreased herbicide efficacy. Thermal-dependency has been established for glutathione reductase, an enzyme involved in herbicide metabolism, in spinach (Spinacia oleraceae L.), corn (Zea mays L.), and cucumber (Cucumis sativus L.) (Mahan et al., 1990). In another study, increasing daily temperatures from $16^{\circ} \mathrm{C} / 10^{\circ} \mathrm{C}$ to $34^{\circ} \mathrm{C} / 28^{\circ} \mathrm{C}$ results in increased metabolism and therefore decreased efficacy of pinoxaden in four winter annual grass species (Matzrafi et al., 2016).

Studying the effect of low temperatures on wheat or weed metabolism is warranted due to the potential for unforeseen temperature-dependent injury following QPE application to CoAXium $^{\mathrm{TM}}$ winter wheat. The objective of our study was to investigate the effect of decreased temperature on QZA content and metabolism after herbicide application in CoAXium ${ }^{\mathrm{TM}}$ winter wheat and three weed species (downy brome [Bromus tectorum L.], feral rye [Secale cereale L.], and jointed goatgrass [Aegilops cylindrica Host]). We focus on herbicide metabolism because of the propensity of this mechanism to overcome injury and the existence of several known cases of hindered herbicide metabolism at low temperatures. Our metabolism measurements, which rely on liquid chromatography coupled to tandem mass spectrometry (LC-MS/MS) to target and quantify QZA in plant tissues, may also serve as an indicator of proherbicide absorption and de-esterification.

\section{MATERIALS AND METHODS \\ Plant Material and Initial Growing Conditions}

Initially, the effect of temperature on QZA metabolism in two winter wheat varieties was investigated. The varieties were CoAXium $^{\mathrm{TM}}$ varieties LCS Fusion AX and Incline AX, both of which were derived from EMS mutagenesis of Hatcher seed and are resistant to QZA through a double homozygous resistance mutation for the ACC1 gene in sub-genomes A and D. The varieties share a pedigree of $\sim 69 \%$ Byrd and $31 \%$ Hatcher. 
TABLE 1 | Overview of growing conditions before and after herbicide application.

\begin{tabular}{lllc}
\hline Description & Duration & $\begin{array}{c}\text { Temperature } \\
\text { ( }{ }^{\circ} \mathbf{C} \text {, day/night) }\end{array}$ \\
\hline Before & Seedling Growth & 2 weeks & $22 / 18$ \\
& Vernalization & 6 weeks & $4.5 / 4.5$ \\
& Dehardening & 10 days & $22 / 18$ \\
After $^{\mathrm{a}}$ & $19^{\circ} \mathrm{C}$ & $16-18$ days & $19 / 4.5$ \\
& $4.5^{\circ} \mathrm{C}$ & $16-18$ days & $4.5 / 4.5$
\end{tabular}

${ }^{a}$ After herbicide application, both temperature conditions were held at $60 \%$ relative humidity with $13.5 \mathrm{~h}$ of daylight providing a photon flux of $132 \mu \mathrm{mol} \mathrm{m} \mathrm{m} \mathrm{sec}^{-1}$.

${ }^{b}$ Treatment duration was 16 days for weed species and 18 days for wheat varieties.

Four wheat seeds were sown per each $1010 \mathrm{~cm}$ container of peat-based soilless media and germinated in a greenhouse. After 2 weeks, seedlings had begun jointing and were moved to a cold room for 6 weeks of vernalization. The cold room was maintained at $4.5^{\circ} \mathrm{C}\left(40^{\circ} \mathrm{F}\right)$ and $60 \%$ relative humidity with $13.5 \mathrm{~h}$ of light provided per day.

The study was expanded to three weedy winter annual grass species: downy brome, feral rye, and jointed goatgrass. Fieldcollected weed seed from northeastern Colorado was surface sterilized with $10 \%$ bleach for $15 \mathrm{~min}$ and rinsed five times with tap water prior to germination on wetted filter paper in petri dishes. Then, weed seedlings were transferred to the same sized containers as wheat with equivalent seedlings per container. Initial growth conditions mirrored those of wheat.

\section{Herbicide Application}

Following vernalization, wheat plants were moved to a greenhouse to de-harden. After a week and a half, QPE (Aggressor, Albaugh, Inc.) was applied at a labeled field rate

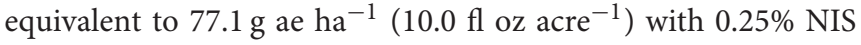
in a single pass at $40 \mathrm{~cm}$ above the plant canopy using a research table sprayer (model Gen IV, Devries Manufacturing, Hollandale, $\mathrm{MN})$. The same protocol was followed for weed species, except for a reduced QPE rate equivalent to $15.0 \mathrm{~g}$ ae ha $\mathrm{ha}^{-1}(1.95 \mathrm{fl} \mathrm{oz}$ acre $^{-1}$ ). Weed species were treated with a reduced rate to avoid fatality and enable metabolism analysis. As per the label, full recommended field rates provide effective control of all weed species. Wheat and weed plants were in the tillering growth stage at the time of herbicide application.

\section{Temperature Conditions}

Half of the plants of each wheat variety and weed species were moved to a controlled environment with a daytime temperature of $19^{\circ} \mathrm{C}$ whereas the other half were moved to a controlled environment with a daytime temperature of $4.5^{\circ} \mathrm{C}$. Both environments featured a nighttime temperature of $4.5^{\circ} \mathrm{C}$ and $60 \%$ relative humidity. Daylengths were $13.5 \mathrm{~h}$ of light providing a photon flux of $132 \mu \mathrm{mol} \mathrm{m} \mathrm{m}^{-2} \mathrm{sec}^{-1}$. Temperature conditions before and after herbicide application are summarized in Table 1.

\section{Metabolism Experimental Design and Harvest}

The overall design for metabolism experiments was a three-way factorial design of two wheat varieties or three weed species by two temperature regimens across five discrete timepoints in two repeated trials. Plants of each wheat variety were harvested from both temperature regimens at $1,2,4,8$, and $18 \mathrm{~d}$ after treatment (DAT), whereas plants of each weed species were harvested at $1,2,4,9$, and 16 DAT. For wheat, each variety and timepoint combination was quintuplicated, with three to four plants comprising a replicate. In the first iteration of the weed metabolism experiment, species and timepoint combination was also quintuplicated, though three to four plants comprised a replicate for downy brome and feral rye and two plants for jointed goatgrass. A weed species replicate in the second trial included four plants. At harvest, wheat and weed shoot tissue was removed, weighed, and washed with $20 \% \mathrm{v} / \mathrm{v}$ acetone in water to remove herbicide residue. Shoots were stored at $-20^{\circ} \mathrm{C}$ until processing.

\section{Herbicide Extraction, Detection, and Quantification}

QZA was extracted from $\sim 2.5 \mathrm{~g}$ of plant tissue using a modified QuEChERS ("quick, easy, cheap, effective, rugged, safe") protocol (Anastassiades et al., 2003; Sack et al., 2015). Samples were first homogenized in $10 \mathrm{~mL}$ distilled water with a homogenizer probe. An equivalent volume of acetonitrile with $0.1 \%$ formic acid was added each sample. Samples were subsequently vortexed, then mixed for $10 \mathrm{~min}$ at room temperature and $250 \mathrm{rpm}$. Each sample was immediately vortexed following the addition of a salt mixture $\left(4 \mathrm{~g} \mathrm{MgSO}_{4}\right.$ and $\left.1 \mathrm{~g} \mathrm{NaCl}\right)$. To induce biphasic separation, samples were centrifuged for $10 \mathrm{~min}$ at room temperature and $4,000 \times$ g. Supernatant from each sample was filtered with $0.2 \mu \mathrm{m}$ PTFE for ultra-pure liquid chromatographic (UPLC) analysis.

The UPLC instrument consisted of a Nexera X2 UPLC with two LC-30 AD pumps, a SiL-30 ACMP autosampler, a DGU20A5 Prominence Degasser, a CTO-30A column oven, and an 8040 triple quadrupole detector (Shimadzu, Kyoto, Japan). A $2.6 \mu \mathrm{m} 100 \times 4.6 \mathrm{~mm}$ reversed-phase C18 column packed with a pore size of $100 \AA$ (Phenomenex Kinetex) was heated to $40^{\circ} \mathrm{C}$ for binary gradient separation. Solvent $\mathrm{A}$ was distilled water with $0.1 \% \mathrm{v} / \mathrm{v}$ formic acid and solvent $\mathrm{B}$ was acetonitrile with $0.1 \% \mathrm{v} / \mathrm{v}$ formic acid. A controller maintained the flow rate at $0.400 \mathrm{~mL}$ $\mathrm{min}^{-1}$. Samples were heated to $400^{\circ} \mathrm{C}$ and ionized using positive electrospray ionization with a $\mathrm{He}$ gas nebulizing flow of $24 \mathrm{~mL}$ $\min ^{-1}$. Desolvation was carried out at $250^{\circ} \mathrm{C}$ with a $\mathrm{He}$ gas drying flow of $24 \mathrm{~mL} \mathrm{~min}^{-1}$. The triple quadrupole filtered nontarget ions using an MRM mode with a Q1 pre-bias of $-24.0 \mathrm{~V}$, a Q2 pre-bias of $-21.0 \mathrm{~V}$, and a Q3 pre-bias of $-21.0 \mathrm{~V}$. Targeted parent ions had a m/z of 345.00 while daughter ions were selected at $299.00 \mathrm{~m} / \mathrm{z}$. The average retention time was $3.2 \mathrm{~min}$.

Samples were grouped by timepoint and replicate number with a randomized temperature regimen order for UPLC analysis in all trials. Samples were injected in $10 \mu \mathrm{L}$ aliquots. Prior to, in the middle of, and after sample runs, serial dilutions of QZA analytical standard ( $\geq 95 \%$, Sigma-Aldrich) in acetonitrile 
with $0.1 \% \mathrm{v} / \mathrm{v}$ formic acid were injected to quantify QZA peak counts through linear calibration curves. Several blank replicates were also included throughout sample runs to monitor method consistency and signal-to-noise ratio. In the first wheat trial, standard concentrations were $2.00,6.00,18.0,54.0,162$, and 486 $\mathrm{pg} \mu \mathrm{L}^{-1}$ while concentrations in the second wheat trial were 2.06,

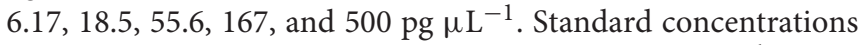

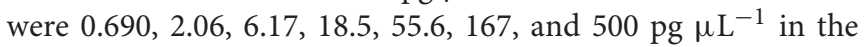
weed trials.

\section{Biomass Experimental Design and Harvest}

The overall design for biomass experiments was a two-way factorial design of the same wheat varieties and weed species from the metabolism experiments. Plants were germinated, grown, treated with herbicide, and exposed to the environmental conditions as described in the first three method sections. Rather than harvesting plants at five timepoints as in the metabolism experiments, plants of each wheat variety and weed species from temperature regimens were harvested at 18 and 16 DAT, respectively. Every wheat variety or weed species by temperature regimen combination had five, replicates comprised of four plants. At harvest, wheat and weed shoot tissue was removed, dried in a drying oven, and weighed for dry biomass.

\section{Statistical Analysis}

All statistical analysis was conducted with packages in RStudio v.1.2.5033 with R v.3.6.2. For each metabolism trial, a linear calibration curve of peak means weighted by standard deviations vs. standard concentration was fit using the stats function of package $1 \mathrm{~m}$ :

$$
y=m x+b
$$

where $y$ is concentration and $x$ is peak area, while $m$ and $b$ are constants. Sample peak areas were converted to concentration using linear calibration curves and were normalized by sample fresh mass before statistical analysis. Individual observations within temperature regimens by variety were screened for outliers using 1.5 interquartile range limits below or above the first or third quartile. Normality and variance diagnostics were used to identify additional outliers and to ensure ANOVA assumptions were fulfilled. Datasets were $\log _{10}$-transformed as necessary to approximate a normal distribution.

Homogeneity of wheat and weed metabolism data across trials was assessed using a Levene's test $(\alpha=0.05)$ to determine if trial data could be pooled. For each trial, a three-way ANOVA ( $\alpha$ $=0.05$ ) was used to evaluate timepoint, temperature regimen, variety or species, and all interactions as significant predictors for herbicide content prior to identification of specific mean differences. Maximum timepoint least square mean estimates of content between temperature regimens per variety as well as content between varieties per temperature regimen were contrasted using F-protected Student's $t$-tests $(\alpha=0.05)$. Further, temperature regimen least square mean estimates at each timepoint were contrasted using F-protected Student's $t$-tests $(\alpha=0.05)$. To determine presence of metabolism within each temperature regimen, timepoint least square mean estimates were compared using Student's $t$-tests with Tukey's HSD multiple comparison adjustments $(\alpha=0.05)$.

Using dry weight data from the biomass experiments, a twoway ANOVA $(\alpha=0.05)$ was used to evaluate temperature regimen, variety or species, and their interaction as significant predictors for biomass. When ANOVA had a significant F-test, biomass values were further contrasted between temperature regimens per variety or species using F-protected Student's $t$ tests $(\alpha=0.05)$. Pairwise comparisons were not conducted if the ANOVA $F$-test was not significant.

\section{RESULTS}

\section{Statistical Overview of the Data}

The Levene's test for homogeneity of data by wheat variety and weed species between trials indicates heterogeneity and therefore cannot be pooled. Efforts were made to account for confounding factors between trials, including germination, vernalization, and environmental conditions (i.e., daylength, light quantity, temperatures, watering, and fertilization), yet the heterogeneity of the data implies an unidentified source of variation. Systematic difference in absolute amounts of QZA detected is related to variations in UPLC and mass spectrometer operating conditions between years, but overall trends in QZA metabolism are consistent between replications in both years for wheat and weeds. For clarity, we present and discuss data from one of the trials hereafter due to the collection of supporting biomass data that was not recorded in one of the trials. The Supplementary Files include data from the duplicate trials for the QZA metabolism experiments in the wheat varieties (Supplementary Table 1 and Supplementary Figure 1) and winter weeds (Supplementary Table 2 and Supplementary Figure 2).

\section{Metabolism of QZA in Winter Wheat and Impact on Dry Biomass}

There are no significant differences for maximum QZA content between temperature regimens for both varieties individually or between maximums by variety at the same temperature (Table 2). Timing of maximum QZA content is also consistent, where maximum content arises at $2 \mathrm{DAT}$ at $19^{\circ} \mathrm{C}$ but is delayed until $8 \mathrm{DAT}$ at $4.5^{\circ} \mathrm{C}$ for both varieties.

Several significant differences exist in QZA content between temperature regimens by timepoint for both wheat varieties (Figure 1). Although LCS Fusion AX has a greater content at $19^{\circ} \mathrm{C}$ than $4.5^{\circ} \mathrm{C}$ for 1 through $4 \mathrm{DAT}$, content is greater at $4.5^{\circ} \mathrm{C}$ for 8 through 18 DAT (Figure 1A). In Incline AX, content is greater under the $19^{\circ} \mathrm{C}$ vs. $4.5^{\circ} \mathrm{C}$ regimen at 1 and $2 \mathrm{DAT}$, the same at $4 \mathrm{DAT}$, and smaller at $19^{\circ} \mathrm{C}$ by 8 and $18 \mathrm{DAT}$ (Figure 1B).

Examining QZA content differences over time for each variety by temperature regimen, significant differences arise in all variety by temperature combinations (Figure 1). Within the $19^{\circ} \mathrm{C}$ treatment of LCS Fusion AX, QZA content remains the same from 1 to $4 \mathrm{DAT}$, decreases by $8 \mathrm{DAT}$, then decreases further by $18 \mathrm{DAT}$ (Figure 1A). In the $4.5^{\circ} \mathrm{C}$ regimen, content stays mostly the same between 1 and 4 DAT, then accumulates until 8 DAT after which content plateaus and remains the 
TABLE 2 | Maximum quizalofop content differences between temperatures per winter wheat variety and by temperature between varieties.

\begin{tabular}{|c|c|c|c|c|c|c|}
\hline Variety & $\begin{array}{l}\text { Temperature } \\
\left({ }^{\circ} \mathrm{C}\right)\end{array}$ & $\begin{array}{c}\text { Maximum content } \\
\left(\log _{10}\left(\mathrm{ng} . \mathrm{g} \mathrm{FW} \mathrm{FW}^{-1}\right) \pm \mathrm{SE}\right)\end{array}$ & & & & $\mathrm{DAT}^{\mathrm{a}}$ \\
\hline \multirow[t]{2}{*}{ LCS Fusion AX } & 19 & $1.22 \pm 0.110$ & $a^{b}$ & $A^{c}$ & & 2 \\
\hline & 4.5 & $1.07 \pm 0.0983$ & $\mathrm{a}$ & & A & 8 \\
\hline \multirow[t]{2}{*}{ Incline AX } & 19 & $1.24 \pm 0.0983$ & a & A & & 2 \\
\hline & 4.5 & $1.13 \pm 0.110$ & $\mathrm{a}$ & & A & 8 \\
\hline
\end{tabular}

a Days after treatment.

${ }^{b}$ There were no significant differences between least square means of temperatures per variety (lowercase letters).

${ }^{c}$ Between varieties (uppercase letters) according to F-protected Student's t-tests ( $\alpha=0.05$ ).

A

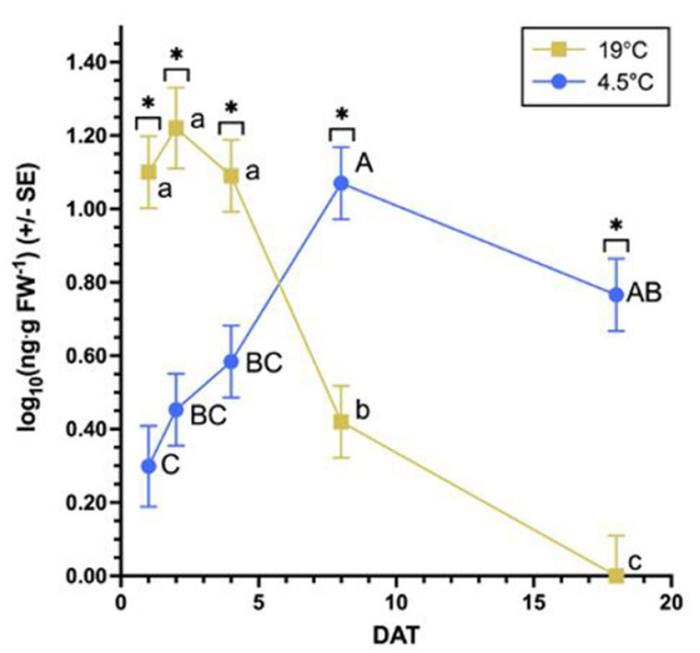

B Incline AX

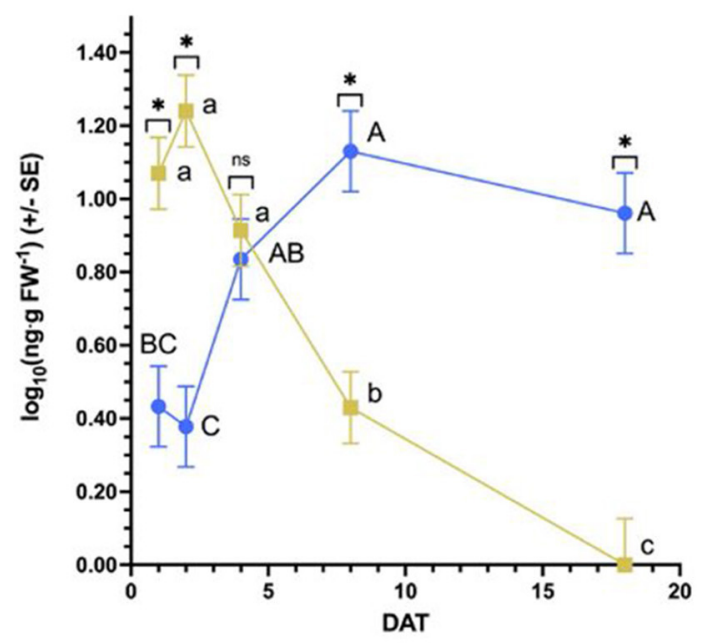

FIGURE 1 | Quizalofop acid content over time per winter wheat variety by temperature. For each variety (A,B), an asterisk specifies significantly different least square means between temperatures at a timepoint, while "ns" indicates no significant differences according to F-protected Student's $t$-tests $(\alpha=0.05)$. By variety, different lowercase letters and capital letters represent significantly different least square means between timepoints at 19 and $4.5^{\circ} \mathrm{C}$, respectively, according to Student's $t$-tests with Tukey's HSD adjustments $(\alpha=0.05)$.

same by 18 DAT. Incline AX exhibits similar trends in both temperature regimens (Figure 1B). Differences between temperature regimens in both varieties reveal a greater QZA content at $19^{\circ} \mathrm{C}$ vs. $4.5^{\circ} \mathrm{C}$, though content at $19^{\circ} \mathrm{C}$ decreases by 4 DAT compared to $4.5^{\circ} \mathrm{C}$. Dry biomass does not significantly differ between temperature regimens for either variety (Figure 2). Moreover, dry biomass does not significantly differ between varieties for either temperature regimen.

\section{Metabolism of QZA in Weed Species and Impact on Dry Biomass}

These are no significant differences for maximum QZA content between temperature regimens for any weed species (Table 3). Across species, jointed goatgrass has the greatest content at $19^{\circ} \mathrm{C}$ whereas downy brome and feral rye have a similar content. Species exhibit similar maximum contents at $4.5^{\circ} \mathrm{C}$. Maximum QZA content timing does vary among species. Maximum QZA content at $19^{\circ} \mathrm{C}$ occurs at 1 and 2 DAT in feral rye and jointed goatgrass, respectively, while maximum content for both species occurs at $9 \mathrm{DAT}$ at $4.5^{\circ} \mathrm{C}$. In downy brome, maximum QZA content appears at $1 \mathrm{DAT}$ in both temperatures.

Several significant differences exist in QZA content between temperature regimens by timepoint per weed species (Figure 3). For downy brome, the only content difference occurs at 9 DAT, where content is greater at $4.5^{\circ} \mathrm{C}$ relative to $19^{\circ} \mathrm{C}$ (Figure 3A). Feral rye has a greater QZA content at $19^{\circ} \mathrm{C}$ than $4.5^{\circ} \mathrm{C}$ at 1 DAT, the same content between temperature regimens at 2 DAT, and a greater content at $4.5^{\circ} \mathrm{C}$ than $19^{\circ} \mathrm{C}$ at 9 and 16 DAT (Figure 3B). Finally, jointed goatgrass has a greater QZA content at $19^{\circ} \mathrm{C}$ than $4.5^{\circ} \mathrm{C}$ at 1 and $2 \mathrm{DAT}$ but reaches greater QZA contents at later timepoints under the $4.5^{\circ} \mathrm{C}$ regimen (Figure 3C). The patterns for feral rye and jointed goatgrass are similar to those of winter wheat, where QZA decreases between 2 and 9 DAT despite a greater initial content at $19^{\circ} \mathrm{C}$ vs. $4.5^{\circ} \mathrm{C}$.

Over time, significant QZA content differences arise for most weed species by temperature combinations (Figure 3). In the $19^{\circ} \mathrm{C}$ regimen of downy brome, QZA content peaks from 1 to 
2 DAT and decreases by 9 DAT, after which content plateaus to 16 DAT (Figure 3A). The $4.5^{\circ} \mathrm{C}$ regimen of downy brome peaks later between 1 and 9 DAT and decreases by 16 DAT. Trends of both feral rye temperature regimens mimic those of downy brome (Figure 3B), though QZA content further decreases from 9 to $16 \mathrm{DAT}$ in the $19^{\circ} \mathrm{C}$ regimen. Jointed goatgrass trends at $19^{\circ} \mathrm{C}$ slightly vary from the other two weed species, where content decreases between 9 and 16 DAT rather than plateauing (Figure 3C). Content across timepoints of the $4.5^{\circ} \mathrm{C}$ regimen of jointed goatgrass does not significantly differ. Dry biomass significantly differs between temperature regimens for jointed goatgrass but no other weed species (Figure 4). Specifically, plants feature a greater biomass at $4.5^{\circ} \mathrm{C}$ than at $19^{\circ} \mathrm{C}$.

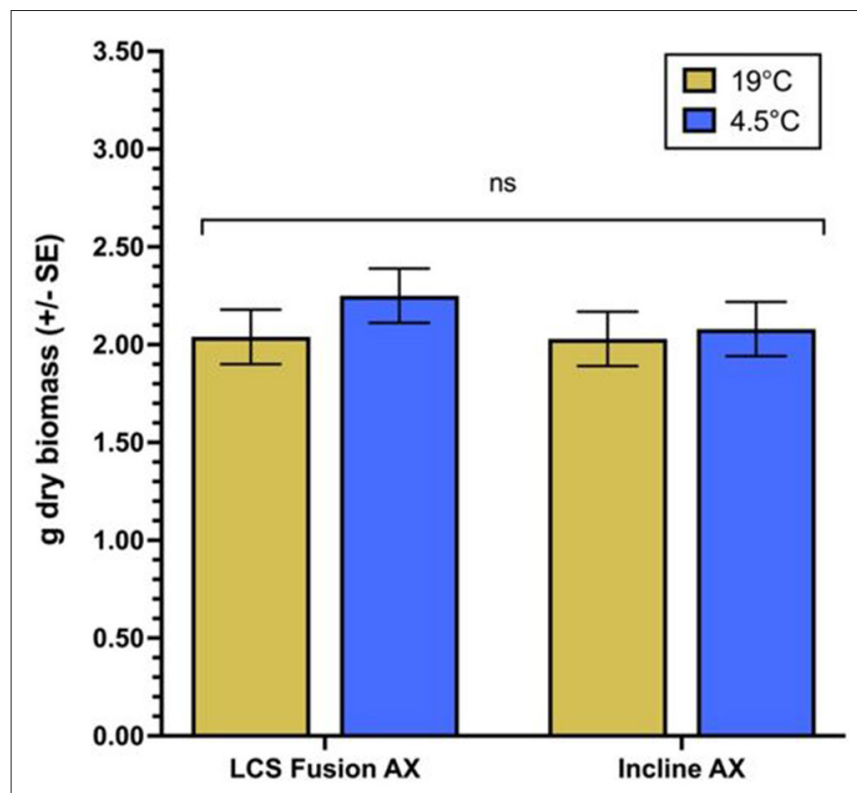

FIGURE 2 | Final dry biomass per winter wheat variety by temperature. ANOVA $F$-tests not significantly different for temperature regime, variety, or their interaction $(\alpha=0.05)$. ns, not significant.

\section{DISCUSSION}

This study assesses the effect of temperature on QZA metabolism under conditions typical of northeastern Colorado dryland wheat production in the High Plains region. The design includes two CoAXium ${ }^{\mathrm{TM}}$ winter wheat varieties adapted to the region and three troublesome winter annual weed species (downy brome, feral rye, and jointed goatgrass) commonly found in North American dryland winter wheat production (Lyon and Baltensperger, 1995; Tautges et al., 2016; Bough et al., 2021). Selected temperature conditions reflect 30-year averages (19912020) in Fort Collins, Colorado during April and May, which feature a daily average high of $19^{\circ} \mathrm{C}$ and low of $4.5^{\circ} \mathrm{C}$ (Western Regional Climate Center, 2021). Further, the Aggressor ${ }^{\mathrm{TM}}$ label advises against herbicide application within 1 week before or after temperatures $<4.5^{\circ} \mathrm{C}$.

\section{Metabolism of QZA in Winter Wheat and Impact on Dry Biomass}

The AXigen trait imparts resistance to QZA. Therefore, QZA content and metabolism was monitored in CoAXium ${ }^{\mathrm{TM}}$ wheat varieties treated with a recommended field rate of QPE $(77.1 \mathrm{~g}$ ae $\left.\mathrm{ha}^{-1}\right)$. Overall, the cooler temperature regimen reduces the rate of QZA metabolism relative to the warmer temperature (Figure 1). This is consistent with previous studies that indicate suppressed herbicide metabolism at cooler temperatures in other grass crops, such as bispyribac in rice (Martini et al., 2015) and metolachlor in corn (Viger et al., 1991). Despite the delayed metabolism of QZA in wheat grown at the cooler temperature compared to the warmer temperature, there was no difference in dry biomass between wheat varieties (Figure 2). This implies that decreased metabolism does not overwhelm the resistance imparted by the AXigen ${ }^{\mathrm{TM}}$ trait at the cooler temperature. A similar study mentions unaffected yield despite visible injury in wheat at 14 days following application of various herbicides at low temperatures in the field (Robinson et al., 2015). Anecdotal field reports of CoAXium ${ }^{\mathrm{TM}}$ injury following Aggressor $^{\mathrm{TM}}$ application at low temperatures may be attributable to inconsequential visual injury.

TABLE 3 | Maximum quizalofop content differences between temperatures per weed species and by temperature among species.

\begin{tabular}{|c|c|c|c|c|c|c|}
\hline Species & $\begin{array}{c}\text { Temperature } \\
\left({ }^{\circ} \mathrm{C}\right)\end{array}$ & $\begin{array}{c}\text { Maximum } \\
\text { content } \\
\text { (ng.g FW } \text { FW }^{-1} \pm \mathrm{SE} \text { ) }\end{array}$ & & & & DAT $^{\mathrm{a}}$ \\
\hline \multirow[t]{2}{*}{ Downy brome } & 19 & $52.3 \pm 4.02$ & $a^{b}$ & $\mathrm{~B}^{\mathrm{C}}$ & & 1 \\
\hline & 4.5 & $57.3 \pm 4.02$ & a & & A & 1 \\
\hline \multirow[t]{2}{*}{ Feral rye } & 19 & $54.4 \pm 5.19$ & a & $\mathrm{B}$ & & 1 \\
\hline & 4.5 & $53.3 \pm 4.02$ & a & & A & 9 \\
\hline \multirow[t]{2}{*}{ Jointed goatgrass } & 19 & $67.7 \pm 4.02$ & a & A & & 2 \\
\hline & 4.5 & $57.2 \pm 4.02$ & a & & A & 9 \\
\hline
\end{tabular}

${ }^{a}$ Days after treatment.

${ }^{b}$ There were no significant differences between least square means of temperatures per species (lowercase letters) according to $F$-protected Student's $t$-tests ( $\alpha=0.05$ ).

${ }^{c}$ Different capital letters represent significantly different least square means within the respective temperatures among species according to F-protected Student's $t$-tests $(\alpha=0.05)$. 

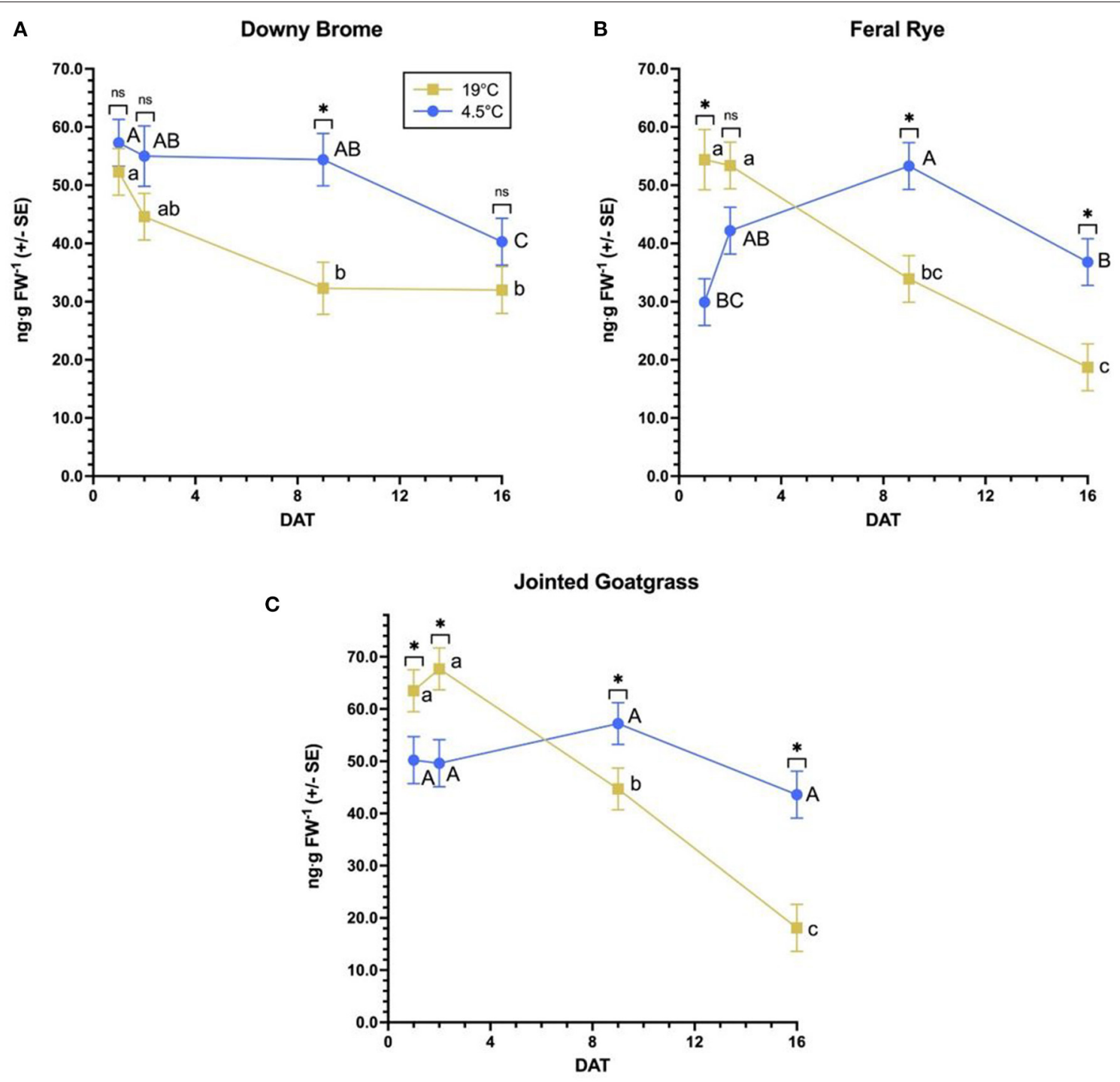

FIGURE 3 | Quizalofop-acid content over time per weed species by temperature. For each species (A-C), an asterisk specifies significantly different least square means between temperatures at a timepoint, while "ns" indicates no significant differences according to F-protected Student's $t$-tests $(\alpha=0.05)$. By species, different lowercase letters and capital letters represent significantly different least square means between timepoints at 19 and $4.5^{\circ} \mathrm{C}$, respectively, according to Student's $t$-tests with Tukey's HSD adjustments $(\alpha=0.05)$.

While metabolism trends in wheat differ as an effect of temperature, maximum QZA contents observed did not vary (Table 2). A greater maximum content in any of the pairwise comparisons would imply greater QPE absorption and/or bioactivation of QPE into QZA by native carboxyesterases. Therefore, in this study, the wheat varieties demonstrate similar absorption and bioactivation irrespective of temperature.

\section{Metabolism of QZA in Weed Species and Impact on Dry Biomass}

QZA content and metabolism in weed species was monitored following the application of a sublethal rate of QPE (15.0 g ae $\mathrm{ha}^{-1}$ ) in order to challenge plants without killing them. The cooler temperature regimen delays QZA metabolism relative to the warmer temperature regimen in all species (Figure 3). Differences reveal a greater initial QZA content in the warmer temperature vs. the cooler temperature, yet imply that all weed species can metabolize QZA in the warmer temperature and significantly reduce content by 4 DAT. Within the cooler temperature regimen, QZA accumulates until 9 DAT and timepoint limitations make subsequent metabolism less certain. Reduced temperatures may increase certain weed species' susceptibility to herbicides and cause growth reductions at lower doses, as seen with the application of mesotrione to waterhemp [Amaranthus tuberculatus (Moq.) Sauer] and large crabgrass [Digitaria sanguinalis (L.) Scop.] under cool temperatures (Johnson and Young, 2002). Increased susceptibility may be attributable to suppressed metabolism. 


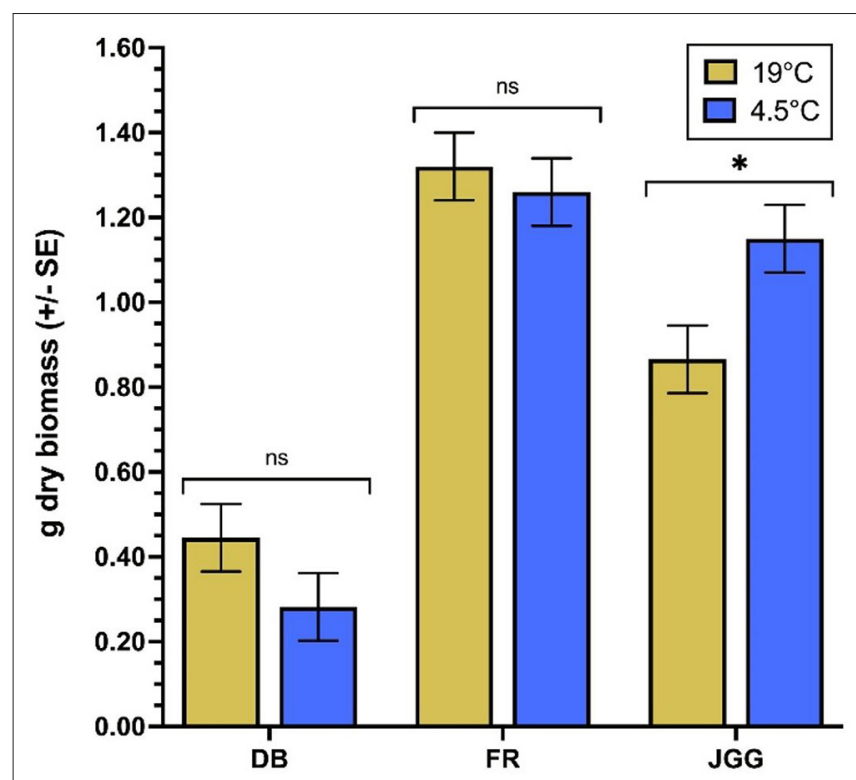

FIGURE 4 | Final dry biomass per weed species by temperature. For each species, an asterisk specifies a significant difference between least square means of temperatures, while "ns" indicates no significant differences according to F-protected Student's $t$-tests $(\alpha=0.05)$. BD, downy brome; FR, feral rye; JGG, jointed goatgrass.

While QZA metabolism in the weed species varies between the cooler and warmer temperature regimens in most cases, the only dry biomass difference between temperatures occurs for jointed goatgrass (Figure 4). For downy brome and feral rye, decreased metabolism at the cooler temperature does not correspond with reduced growth, whereas the cooler temperature regimen surprisingly results in greater biomass than the warmer temperature in jointed goatgrass. On occasion, sublethal herbicide doses may induce hormesis, or a stimulating effect on plants depending on species, developmental stage, environmental conditions, and herbicide (Belz and Duke, 2014). Minimal stress or herbicide doses essentially elicit overcompensation responses. A field study of barley (Hordeum vulgare L.) indicates that sublethal glyphosate or metsulfuron doses stimulate biomass growth by about $25 \%$, though sublethal doses of other herbicides, including haloxyfop, do not (Cedergreen, 2008). In our study, the sublethal herbicide dose in combination with the cooler temperature regimen in jointed goatgrass likely incites a hormetic response to overcompensate for the dual presence of QZE and cold stress. A previous study in sugarcane (Saccharum officinarum L.) and eucalyptus (Eucalyptus grandis W. Hill) relates the hormetic effect of sublethal glyphosate doses to enhanced photosynthesis through increased $\mathrm{CO}_{2}$ assimilation, stomatal conductance, and transpiration (Nascentes et al., 2018).

As with wheat, weed species reach similar maximum QZA contents between temperature regimens (Table 3), illustrating that QPE absorption and bioactivation of QPE into QZA was the same at the two temperature regimens used in this study. Comparatively, other studies report decreased herbicide absorption at cooler temperatures in some grass weeds, including nicosulfuron in quackgrass [Elymus repens (L.) Gould] and metribuzin in downy brome as well as jointed goatgrass (Buman et al., 1992; Bruce et al., 1996). Differences in the literature may be attributable to experimental design considerations and the utilization of more precise methods to measure absorption rather than the use of maximum QZA content as a proxy for absorption. Further, the absence of a timing difference for maximum QZA content in downy brome suggests that the cooler temperature regimen affected absorption to a lesser extent than the other weed species. Trends and timepoint differences in Figure 3 corroborate this inference, as content in the cooler temperature regimen remains the same from 1 to 9 DAT for downy brome.

\section{CONCLUSIONS}

The capacity of CoAXium ${ }^{\mathrm{TM}}$ wheat varieties to metabolize QZA is reduced at the cooler temperature regimen but not sufficiently to overcome the protection to this herbicide afforded by the AXigen ${ }^{\mathrm{TM}}$ resistance trait, resulting in no impact on biomass accumulation. Anecdotal field reports of CoAXium ${ }^{\mathrm{TM}}$ injury following Aggressor ${ }^{\mathrm{TM}}$ application at low temperatures may be attributable to inconsequential visual injury or due to multiple other stress factors, though follow-up field studies are necessary to elucidate the causes of injury. All weed species have some capacity to metabolize QZA under both temperature conditions except for jointed goatgrass in the cooler temperature regimen, but as with wheat, the cooler temperature regimen generally delays metabolism. Weed species biomass only differs between temperatures for jointed goatgrass, which undergoes a hormetic response in response to sublethal herbicide doses in combination with cold stress, causing greater biomass accumulation in the cooler temperature regimen compared to the warmer temperature. A lack of differences in maximum QZA content between temperature regimens in both wheat and weeds suggests similar rates of QPE absorption and QZE bioactivation. Further experiments measuring QPE in addition to QZE with UPLC-MS/MS or conventional radiochemical assays can validate similar absorption and bioactivation at disparate temperatures.

Climate change, including low or high temperature extremes, may impact the efficacy of current weed management strategies. Elevated temperatures and $\mathrm{CO}_{2}$ levels reduce the efficacy of many pesticides by altering xenobiotic metabolism and translocation in target organisms (Matzrafi, 2019). Reduced efficacy corresponds to increased herbicide resistance in weeds due to decreased herbicide persistence in soil and a greater capacity for herbicide metabolism (Refatti et al., 2019; Korres and Dayan, 2020). In particular, ACCase-inhibitor efficacy tends to decrease at elevated temperatures, including that of diclofop, pinoxaden, and fluazifop (Smeda and Putnam, 1990; Matzrafi et al., 2016). Our study provides further evidence of quizalofop metabolism 
thermal dependence which may translate to altered efficacy. The thermal dependence of herbicide metabolism pathways should be considered when applying ACCase-inhibitors to avoid non-target plant injury and to maximize efficacy on target weeds.

\section{DATA AVAILABILITY STATEMENT}

The original contributions presented in the study are included in the article/Supplementary Material, further inquiries can be directed to the corresponding author/s.

\section{AUTHOR CONTRIBUTIONS}

$\mathrm{RB}$ and FD conceived and designed the methods and experiments and also drafted the manuscript. RB conducted the experiments and performed data analysis. TG and FD provided suggestions on experiments. TG edited the manuscript. All authors contributed to the article and approved the submitted version.

\section{REFERENCES}

Anastassiades, M., Lehotay, S. J., Stajnbaher, D., and Schenck, F. (2003). Fast and easy multiresidue method employing acetonitrile extraction/partitioning and "dispersive solid-phase extraction" for the determination of pesticide residues in produce. J. AOAC Int. 86, 412-431. doi: 10.1093/jaoac/ 86.2.412

Belz, R. G., and Duke, S. O. (2014). Herbicides and plant hormesis. Pest Manag. Sci. 70, 698-707. doi: 10.1002/ps.3726

Bough, R. A., and Dayan, F. E. (2021). Biochemical and structural characterization of quizalofop-resistant wheat acetyl-CoA carboxylase. Sci. Rep. doi: 10.21203/rs.3.rs-852099/v1

Bough, R. A., Westra, P., Gaines, T. A., Westra, E. P., Haley, S., Erker, B., et al. (2021). The coaxium wheat production system: a new herbicide-resistant system for annual grass weed control and integrated weed management. Outlooks Pest Manag. 32, 151-157. doi: 10.1564/v32_aug_04

Bruce, J. A., Carey, J. B., Penner, D., and Kells, J. J. (1996). Effect of growth stage and environment on foliar absorption, translocation, metabolism, and activity of nicosulfuron in quackgrass (Elytrigia repens). Weed Sci. 44, 447-454. doi: 10.1017/S0043174500094170

Buman, R. A., Gealy, D. R., and Ogg, A. G. J. (1992). Effect of temperature on root absorption of metribuzin and its ethylthi analog by winter wheat (Triticum aestivum), jointed goatgrass (Aegilops cylindrica), and downy brome (Bromus tectorum). Weed Sci. 40, 517-521. doi: 10.1017/S0043174500058069

Cedergreen, N. (2008). Herbicides can stimulate plant growth. Weed Res. 48, 429-438. doi: 10.1111/j.1365-3180.2008.00646.x

Cummins, I., and Edwards, R. (2004). Purification and cloning of an esterase from the weed black-grass (Alopecurus myosuroides), which bioactivates aryloxyphenoxypropionate herbicides. Plant J. 39, 894-904. doi: 10.1111/j.1365-313X.2004.02174.x

Ganie, Z. A., Jugulam, M., and Jhala, A. J. (2017). Temperature influences efficacy, absorption, and translocation of 2,4-D or glyphosate in glyphosateresistant and glyphosate-susceptible common ragweed (Ambrosia artemisiifolia) and giant ragweed (Ambrosia trifida). Weed Sci. 65, 588-602. doi: $10.1017 /$ wsc. 2017.32

Ghanizadeh, H., and Harrington, K. C. (2017). Non-target site mechanisms of resistance to herbicides. Crit. Rev. Plant Sci. 36, 24-34. doi: 10.1080/07352689.2017.1316134

Haslam, R., Raveton, M., Cole, D. J., Pallett, K. E., and Coleman, J. O. D. (2001). The identification and properties of apoplastic carboxylesterases from wheat that catalyse deesterification of herbicides. Pestic. Biochem. Physiol. 71, 178-189. doi: $10.1006 /$ pest.2001.2575
FUNDING

This research was funded by the Colorado Wheat Research Foundation (CWRF), grant number 5303094 and the USDA National Institute of Food and Agriculture, Hatch Project 1016591, COL00785, and COL00783.

\section{ACKNOWLEDGMENTS}

The authors thank CWRF for inspiring the overall study objective. Samples were harvested and processed through the assistance of Catherine Miller, Stephen Corcillo, and Amber Pelon.

\section{SUPPLEMENTARY MATERIAL}

The Supplementary Material for this article can be found online at: https://www.frontiersin.org/articles/10.3389/fagro. 2021.800731/full\#supplementary-material

Johnson, B. C., and Young, B. G. (2002). Influence of temperature and relative humidity on the foliar activity of mesotrione. Weed Sci. 50, 157-161. doi: 10 . 1614/0043-1745(2002)050[0157:IOTARH]2.0.CO2

Korres, N. E., and Dayan, F. E. (2020). Effects of climate change on crops and weeds: the need for climate-smart adaptation paradigm. Outlooks Pest Manag. 31, 210-215. doi: 10.1564/v31_oct_04

Kudsk, P., and Kristensen, J. L. (1992). "Effect of environmental factors on herbicide performance," in Proceedings of the First International Weed Control Congress (Victoria, TX: Weed Science Society of Victoria Inc.), 173-186.

Lyon, D. J., and Baltensperger, D. D. (1995). Cropping systems control winter annual grass weeds in winter wheat. J. Prod. Agric. 8, 459-539. doi: 10.2134/jpa1995.0535

Mahan, J. R., Burke, J. J., and O'rzech, K. A. (1990). Thermal dependence of the apparent $\mathrm{Km}$ of glutathione reductases from three plant species. Plant Physiol. 93, 822-824. doi: 10.1104/pp.93.2.822

Mahan, J. R., Dotray, P. A., and Light, G. G. (2004). Thermal dependence of enzyme function and inhibition; implications for, herbicide efficacy and tolerance. Physiol. Plant 120, 187-195. doi: 10.1111/j.0031-9317.2004.0255.x

Martini, L. D. F., Roma-Burgos, N., Tseng, T. M., Fipke, V. M., Noldin, A. J., and De Avila, L. A. (2021). Acclimation to cold stress reduces injury from low temperature and bispyribac-sodium on rice. Pest Manag. Sci. 77, 4016-4025. doi: $10.1002 /$ ps. 6425

Martini, L. F., Burgos, N. R., Noldin, J. A., De Avila, L. A., and Salas, R. A. (2015). Absorption, translocation and metabolism of bispyribacsodium on rice seedlings under cold stress. Pest Manag. Sci. 71, 1021-1029. doi: $10.1002 /$ ps.3882

Matzrafi, M. (2019). Climate change exacerbates pest damage through reduced pesticide efficacy. Pest Manag. Sci. 75, 9-13. doi: 10.1002/ps.5121

Matzrafi, M., Seiwert, B., Reemtsma, T., Rubin, B., and Peleg, Z. (2016). Climate change increases the risk of herbicide-resistant weeds due to enhanced detoxification. Planta 244, 1217-1227. doi: 10.1007/s00425-016$2577-4$

Nascentes, R. F., Carbonari, C. A., Simoes, P. S., Brunelli, M. C., Velini, E. D., and Duke, S. O. (2018). Low doses of glyphosate enhance growth, $\mathrm{CO}_{2}$ assimilation, stomatal conductance and transpiration in sugarcane and eucalyptus. Pest Manag. Sci. 74, 1197-1205. doi: 10.1002/ps.4606

Ostlie, M., Haley, S. D., Anderson, V., Shaner, D., Manmathan, H., Beil, C., et al. (2015). Development and characterization of mutant winter wheat (Triticum aestivum L.) accessions resistant to the herbicide quizalofop. Theor. Appl. Genet. 128, 343-351. doi: 10.1007/s00122-014-2434-4

Refatti, J. P., De Avila, L. A., Camargo, E. R., Ziska, L. H., Oliveira, C., SalasPerez, R., et al. (2019). High $\left[\mathrm{CO}_{2}\right]$ and temperature increase resistance to 
cyhalofop-butyl in multiple-resistant Echinochloa colona. Front. Plant Sci. 10:529. doi: 10.3389/fpls.2019.00529

Robinson, M. A., Letarte, J., Cowbrough, M. J., Sikkema, P. H., and Tardif, F. J. (2015). Winter wheat (Triticum aestivum L.) response to herbicides as affected by application timing and temperature. Can. J. Plant Sci. 95, 325-333. doi: 10.4141/cjps-2014-109

Sack, C., Vonderbrink, J., Smoker, M., and Smith, R. E. (2015). Determination of acid herbicides using modified QuEChERS with fast switching ESI(+)/ESI(-) LC-MS/MS. J. Agric. Food Chem. 63, 9657-9665. doi: 10.1021/acs.jafc.5b04093

Smeda, R. J., and Putnam, A. R. (1990). Influence of temperature, rainfall, grass species, and growth stage on efficacy of fluazifop. Weed Technol. 4, 349-355. doi: $10.1017 /$ S0890037X00025525

Tautges, N. E., Burke, I. C., Borrelli, K., and Fuerst, E. P. (2016). Competitive ability of rotational crops with weeds in dryland organic wheat production systems. Renew. Agric. and Food Sys. 32, 57-68. doi: 10.1017/S1742170516000028

Viger, P. R., Eberlein, C. V., Fuerst, E. P., and Gronwald, J. W. (1991). Effects of CGA-154281 and temperature on metolachlor absorption and metabolism, glutathione content, and glutathione-S-transferase activity in corn (Zea mays). Weed Sci. 39, 324-328. doi: 10.1017/S0043174500073008

Western Regional Climate Center (2021). Fort Collins 4 E, CO: Average of Minimum Temperature (Degrees Fahrenheit). Available online at: https://
wrcc.dri.edu/WRCCWrappers.py?sodxtrmts+053006+por+por+mint+none+ mave $+5+01+\mathrm{F}$ (accessed October 23, 2021).

Conflict of Interest: The authors declare that the research was conducted in the absence of any commercial or financial relationships that could be construed as a potential conflict of interest.

Publisher's Note: All claims expressed in this article are solely those of the authors and do not necessarily represent those of their affiliated organizations, or those of the publisher, the editors and the reviewers. Any product that may be evaluated in this article, or claim that may be made by its manufacturer, is not guaranteed or endorsed by the publisher.

Copyright (c) 2022 Bough, Gaines and Dayan. This is an open-access article distributed under the terms of the Creative Commons Attribution License (CC BY). The use, distribution or reproduction in other forums is permitted, provided the original author(s) and the copyright owner(s) are credited and that the original publication in this journal is cited, in accordance with accepted academic practice. No use, distribution or reproduction is permitted which does not comply with these terms. 